\title{
Роль синхронности в геофизических исследованиях горно-геологических структур
}

Дьяков А.Ю., Калашник А.И.

Горный институт КНЦРАН, Anamumbl,dyakov@goi.kolasc.net.ru; kalashnik@goi.kolasc.net.ru

Аннотация. В статье приведены результаты комплексных геофизических исследований на наблюдательном полигоне ограждающей дамбы хвостохранилища $\mathrm{AO}$ «Ковдорский ГОК» различными по природе волновыми методами: георадиолокационным и сейсмическим зондированием. Выполнен сопоставительный анализ результатов сейсмических и георадиолокационных синхронных и не синхронных исследований, который по данным отношения скоростей продольной и поперечной упругой волны позволил установить границы зон и интервалы скоростей электромагнитной волны при переходе из сухих, плотных грунтов в увлажненные и, далее, в водонасыщенные. Установлено, что слагающие дамбу грунты находятся во влажном и водонасыщенном состоянии. Исследованиями уточнена структура ограждающей дамбы и подстилающего основания, а также выявлена зональная фильтрационная неоднородность слагающих дамбу грунтов. На основе вычисленного коэффициента корреляции значений скоростей электромагнитной и сейсмической волны выявлено, что синхронизация геофизических исследований позволяет существенно повысить достоверность полевых определений, а также получить более надежные данные.

Ключевые слова: ограждающая дамба, хвостохранилище, водонасыщение, георадиолокационное зондирование, сейсмическое зондирование, скорость волны, синхронность.

\section{The role of synchronicity in geophysical studies of mining and geological structures}

\author{
Dyakov A.Yu., Kalashnik A.I. \\ MiningInstitute KSCRAS, Apatity,dyakov@goi.kolasc.net.ru; kalashnik@goi.kolasc.net.ru
}

\begin{abstract}
The article presents the results of complex geophysical studies at the observation site of the fencing of the tailing dump of JSC Kovdorsky GOK by wave methods of different nature: georadar and seismic sounding. A comparative analysis of the results of seismic and georadar synchronous and non-synchronous studies was carried out, which, according to the ratio of the velocities of the longitudinal and transverse elastic waves, made it possible to establish the boundaries of the zones and the intervals of the electromagnetic wave velocities during the transition from dry, dense soils to wet and then saturated. It is established that the components of the dam soils are in a wet and water-saturated state. Studies have refined the structure of the enclosing dam and underlying foundation, and also identified zonal filtration heterogeneity of the components of the dam soils. Based on the calculated correlation coefficient of the values of the electromagnetic and seismic wave velocities, it was revealed that the synchronization of geophysical studies can significantly increase the reliability of field definitions, as well as obtain more reliable data.

Key words: fencing dam, tailing, water saturation, GPR sounding, seismic sounding, wave speed, synchronization.
\end{abstract}

\section{Введение}

В настоящее время основными тенденциями геофизики при исследовании горно-геологических структур является повышение информативности и надежности получаемых данных. Существование большого количества методов геофизики свидетельствует об отсутствии какого-то одного стандартного геофизического метода, способного обеспечить оперативное и качественное получение требуемой информации о горно-геологической среде, ввиду сложности и неоднозначности получаемых данных. Поэтому рациональный выбор и комплексирование геофизических методов позволяет повысить уровень и надежность данных при решении различных задач. В свою очередь, оценка изменений состояния горно-геологических структур, обусловленных как техногенными, так и природными факторами, накладывает более жесткие требования на комплексирование методов, а также синхронности измерений для получения единых данных, отражающих структуру. Целью данного исследования являлось изучение роли синхронности при комплексных геофизических иссле- 
дованиях грунтовых горно-геологических структур, в частности, ограждающей дамбы хвостохранилища, для изучения ее подповерхностной структуры и локализации зон различной водонасыщенности грунтов в ее теле. Система ограждающих дамб и хвостохранилище представляют собой ответственное гидротехническое сооружение, эксплуатация которого должна выполняться в строгом соответствии с требованиями промышленной безопасности. Нарушение устойчивости и функциональности ограждающих дамб может привести к аварийной ситуации и значительному социальноэкономическому ущербу. Так, в 2013 г. и 2017 г. произошли интенсивные протечки и размывы нижнего склона ограждающей дамбы хвостохранилища АО «Ковдорский ГОК», приведшие к необходимости дополнительных исследований гидротехнического сооружения (Данилкин и др., 2014; Калашник и др., 2013, 2017, 2018; Мельников и др., 2010, 2016, 2017).

\section{Результаты}

В 2013 и 2017 году на наблюдательном полигоне дамбы хвостохранилища АО «Ковдорский ГОК», в целях уточнения границ вариаций контрольных геофизических показателей при локализации зон водонасыщения и намокания грунтов, выполнен цикл наблюдений сейсмическим и георадарным методами, где в качестве показателей результатов приняты: Vs/Vp - для сейсмического метода; V - скорость прохождения электромагнитной волны для георадарного метода наблюдений. Основные результаты выполненных синхронных исследований представлены в виде радарограммы скорости электромагнитной волны $\mathrm{V}$ (a) и сейсмотомограммы соотношения сейсмических скоростей $\mathrm{Vs} / \mathrm{Vp}$ (б) (рис. 1). На палитрах, выделенных по вышеуказанным показателям зон, визуально отмечается подобие в распределениях исследуемых разрезов, что отражает структурные особенности обследуемого участка. Для количественного сопоставления результатов построены графики изменчивости контролируемых показателей по трассам зондирования в отдельных разрезах на двух пикетах (рис. 2).

Интерпретация анализируемых результатов 2017 г. позволяет сделать следующие выводы. Приповерхностная зона до 289.5-289 м (1-1.5м), подверженная проникновению осадков, характе-

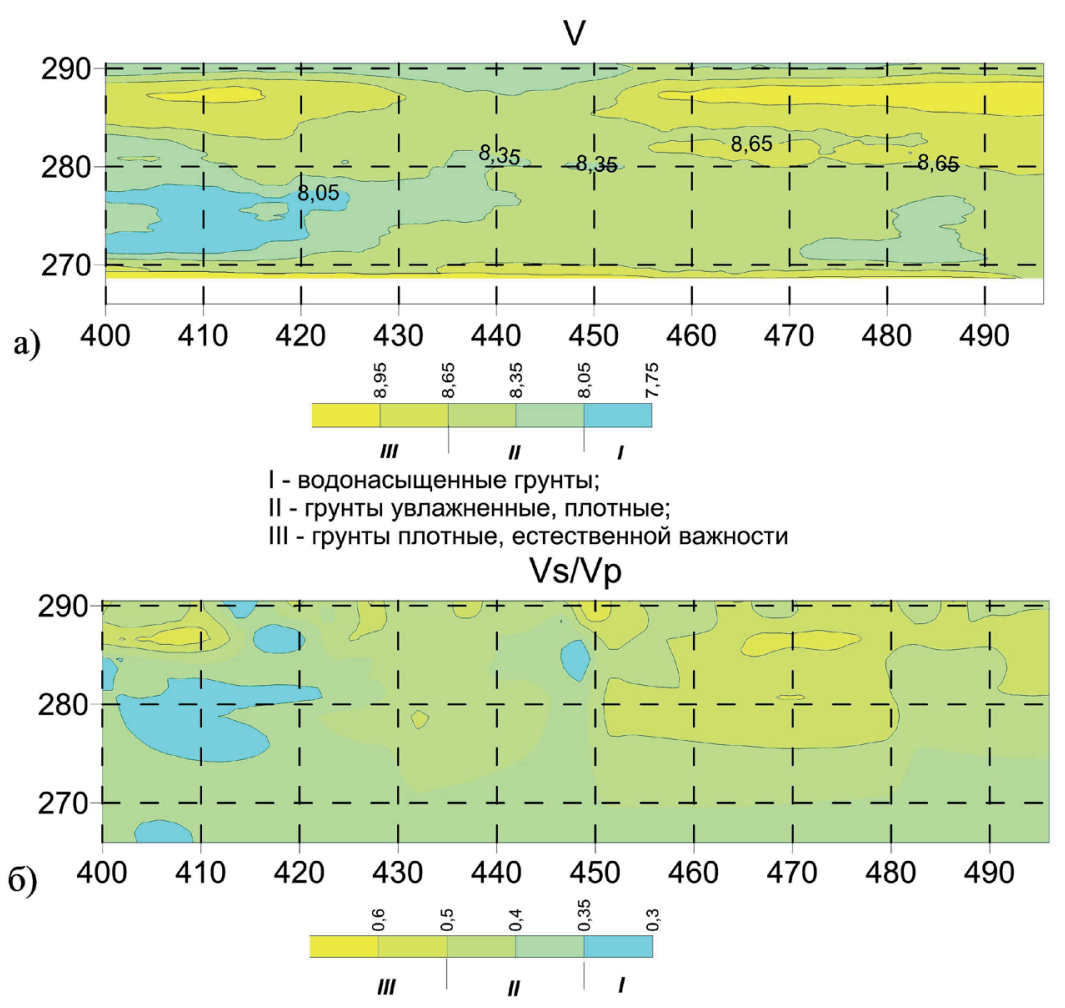

Рис. 1. Результаты синхронного георадарного (а) и сейсмического (б) зондирования дамбы 2017 г.

Fig. 1. Results of synchronous georadar (a) and seismic (b) sounding of the dam 2017. 

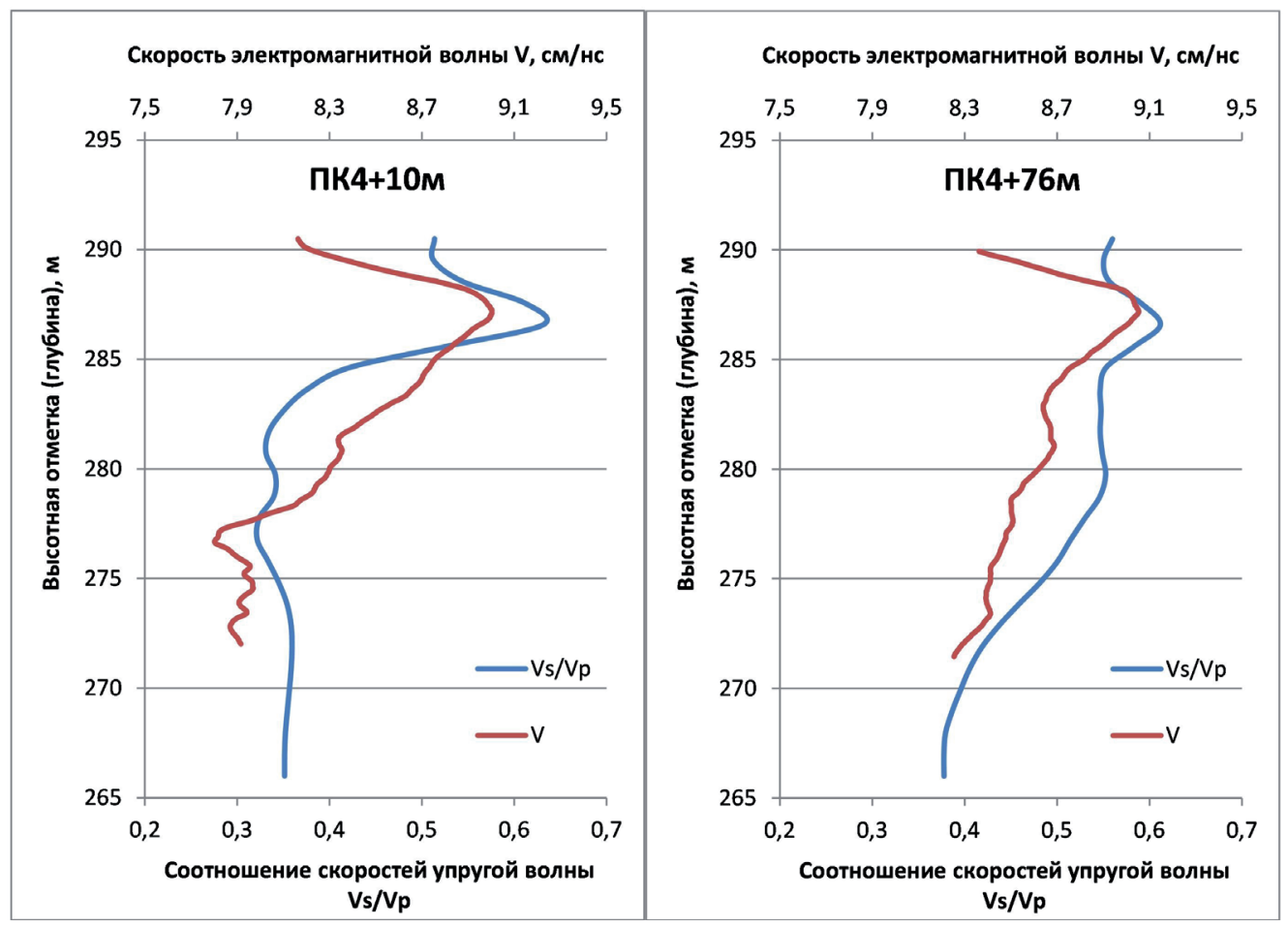

Рис. 2. Сопоставление результатов наблюдений 2017 г. георадарным (V) и сейсмическим (Vs/Vp) зондированием по трассам в сечениях дамбы.

Fig. 2. Comparison of the results of observations in 2017 by georadar (V) and seismic (Vs/Vp) sounding along the routes in the dam sections.
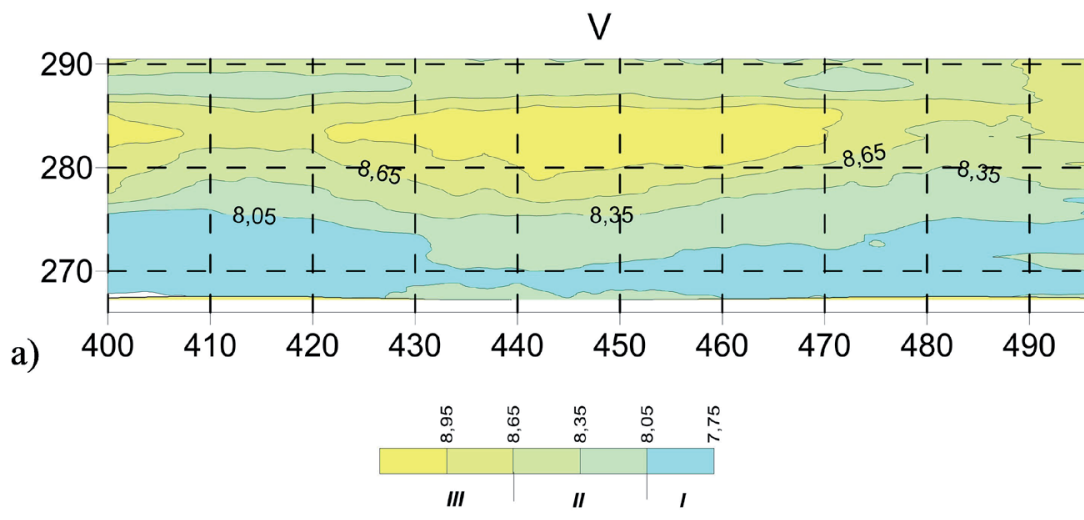

$\mathrm{Vs} / \mathrm{Vp}$
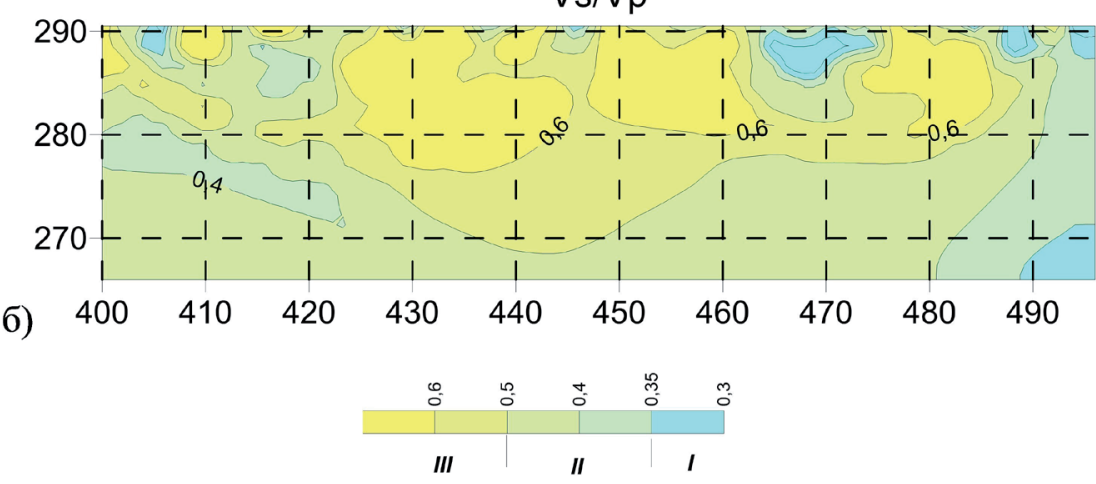

Рис. 3. Результаты зондирования дамбы 2013 г. георадарным (а) и сейсмическим (б) методами.

Fig. 3. Results of dam sounding in 2013 by georadar (a) and seismic (b) methods. 


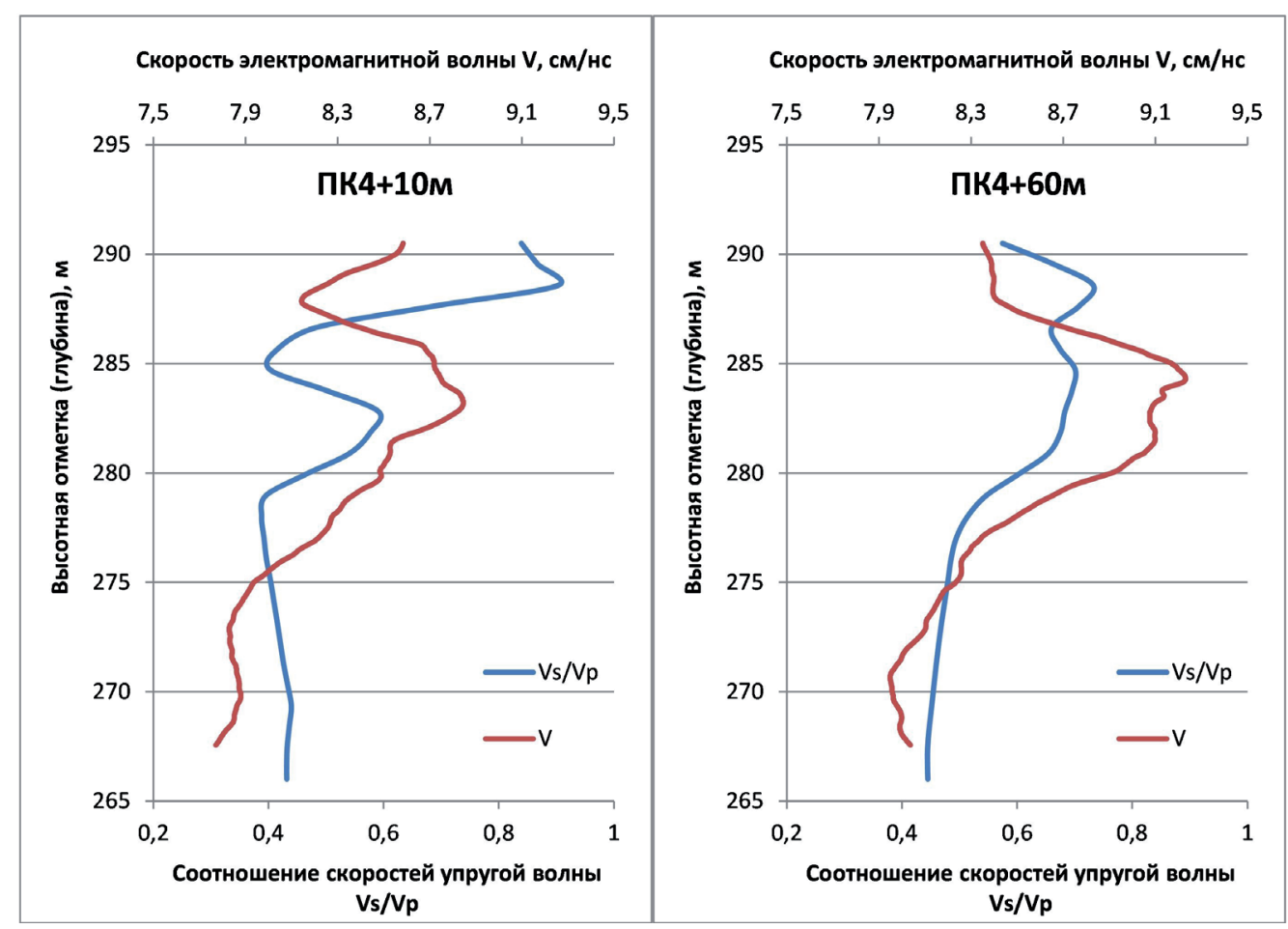

Рис. 4. Сопоставление результатов наблюдений 2013 г. георадарным (V) и сейсмическим (Vs/Vp) зондированием по трассам в сечениях дамбы.

Fig. 4. Comparison of the results of the observations of 2013 by georadar (V) and seismic (Vs/Vp) sounding along the routes in the dam sections.

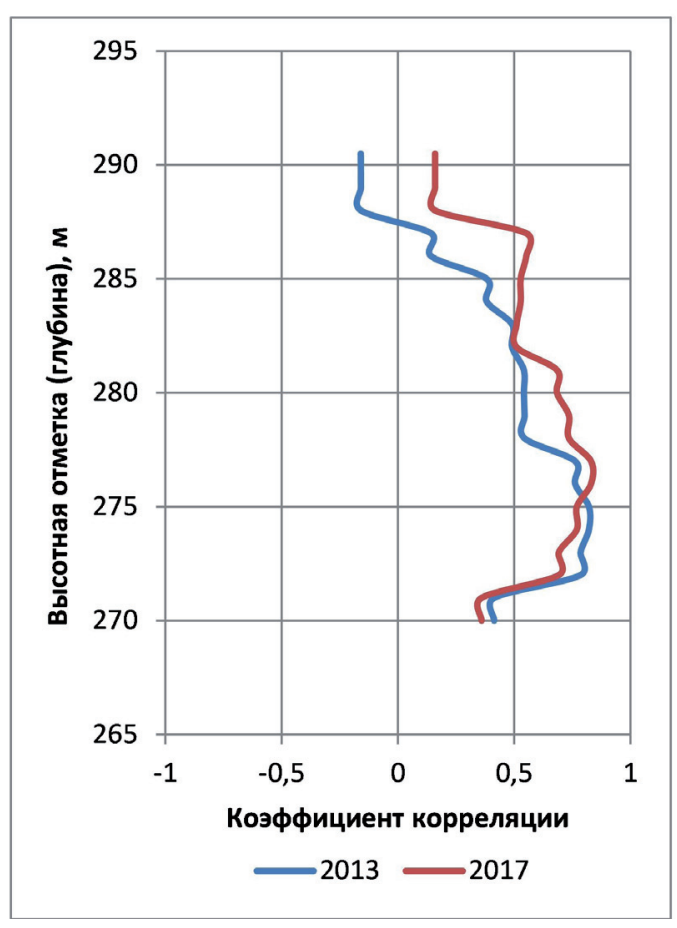

Рис. 5. Коэффициент корреляции связи скоростей электромагнитных волн $\mathrm{V}$ и соотношения скоростей упругой волны $\mathrm{Vs} / \mathrm{Vp}$.

Fig. 5. The correlation coefficient of the coupling of the velocities of electromagnetic waves $\mathrm{V}$ and the ratio of the velocities of the elastic wave $\mathrm{Vs} / \mathrm{Vp}$. ризуется начальной невысокой скоростью $\mathrm{V}=8.1$ $8.22 \mathrm{~cm} / \mathrm{нc}$, с дальнейшим резким ее нарастанием до $\mathrm{V}=8.36-8.71$ см/нс на глубине 282.5-280 м (8-10 м), что обусловлено, скорее всего, ростом плотности и снижением влажности грунтов. В интервале высотных отметок 280-270 м фиксируется зона резкого падения величин скоростей до значений $\mathrm{V}=7.35-7.71 \mathrm{~cm} / \mathrm{нc}$. Глядя на подобные изменения показателя $\mathrm{Vs} / \mathrm{Vp}$ на этих же отметках и составляющего 0.30-0.35 по сейсмотомограмме (рис. 1, б - голубая палитра рисунка), можно заключить, что грунты здесь подвержены значительному намоканию.

Интерпретация результатов 2013 г. (рис. 3) позволяет сделать следующие выводы. Анализ палитры выделенных зон по вышеуказанным критериям показал визуальное несоответствие в распределениях скоростей исследуемых разрезов, отражающих структурные особенности обследуемого участка. По данным георадиолокации приповерхностная зона на глубину до 2 м. представлена увлажненными грунтами на двух интервалах 400-430 м, 470-480 м, в свою очередь по данным сейсмического метода приповерхностная зона увлажнена только очень небольшими локальными участками до 5 м шириной, и только в конце профиля 470 м совпадает с данными георадиолокации. 
По данным сейсмического метода водонасыщенные грунты выделяются в самом конце профиля на интервале 485-498 м на всю глубину разреза, а по данным георадиолокации водонасыщенные грунты определяются по всей длине профиля на абсолютной отметке 270-275 м. Такие изменения можно объяснить не единовременным комплексированием методов, разница во времени измерений составила несколько дней, а также влиянием природных (обильные осадки) и техногенных факторов (сброс воды с фабрики), которые также нельзя исключать. Однако в центральной части профиля данные имеют очень хорошую повторяемость, здесь повсеместно плотные грунты естественной влажности. Для более конкретного сопоставления результатов представлены графики (рис. 4) изменчивости контролируемых показателей в отдельных разрезах на двух пикетах.

Сравнение данных георадарного и сейсмического зондирования показало наличие уверенной корреляции (сходимости) полученных результатов. Однако данные 2017 имеют более тесную связь (рис. 5), что связано с комплексированием данных методов в пространственно-временной увязке.

\section{Заключение}

Выполнены комплексные геофизические исследования для целей оценки состояния ограждающей дамбы АО Ковдорского ГОКа. Проведенные работы позволили оценить состояние дамбы и выявить локальные зоны повышенного водонасыщения и фильтрации. Установлено, что слагающие дамбу грунты находятся во влажном и водонасыщенном состоянии. Выявлена зональная фильтрационная неоднородность слагающих дамбу грунтов, уточнена структура ограждающей дамбы и подстилающего основания. На основе вычисленного коэффициента корреляции значений скоростей электромагнитной и сейсмической волны выявлено, что синхронизация геофизических исследований позволяет существенно повысить достоверность полевых определений, а также получить более надежные данные. Результаты проведенных исследований представляют собой основу для прогнозирования наиболее уязвимых мест (зон) насыпного грунтового гидротехнического сооружения, а так же локализацию водонасыщенных участков в теле грунтовых сооружений с большей надежностью и технологичностью.

\section{Литература}

1. Данилкин А.А., Калашник А.И., Запорожец Д.В., Максимов Д.А. Мониторинг состояния ограждающей дамбы в зоне отработки техногенного месторождения Ковдорского ГОКа // ГИАБ. 2014. № 7. С. 344-351.

2. Калашник А.И., Запорожец Д.В., Калашник Н.А. Идентификация фильтрационно-деформационных процессов в теле ограждающей дамбы хвостохранилища // Вестник Кольского научного центра РАН. 2013. № 2. С. 13-16.

3. Калашник А.И., Дьяков А.Ю. Информационные технологии в задачах мониторинга гидротехнических сооружений горнодобывающих предприятий подповерхностным георадиолокационным зондированием // Горный информационно-аналитический бюллетень (научно-технический журнал). 2017. № S23. С. 283-291.

4. Калашник А.И., Дьяков А.Ю., Абрамов Н.Н. Комплексирование георадарного и сейсмического зондирования дамбы хвостохранилища // Известия высших учебных заведений. Горный журнал. 2018. № 4. С. 104-111.

5. Мельников Н.Н., Калашник А.И. Определение подповерхностной структуры и мониторинг состояния природно-технических систем // Север промышленный. 2010. № 4 (34). С. 50-51.

6. Мельников Н.Н., Калашник А.И., Запорожец Д.В., Дьяков А.Ю., Максимов Д.А. Опыт применения георадарных подповерхностных исследований в западной части российского сектора Арктики // Проблемы Арктики и Антарктики. 2016. № 1. С. 39-49.

7. Мельников Н.Н., Калашник А.И., Калашник Н.А., Запорожец Д.В. Применение современных методов для комплексных исследований состояния гидротехнических сооружений региона Баренцева моря // Вестник МГТУ. 2017. Т. 20. № 1 (1). С. 13-20. 